\title{
Erişkin hastalarda 498 deri altı port kateter uygulamaları ve komplikasyonlarının retrospektif değerlendirilmesi
}

\author{
Retrospective evaluation of 498 venous access port implantations and complications \\ in adult patients
}

Tuğba Eldeş, İlkay Akmangit, Doğan Dede, Nilgün Yıldırım, Bige Sayın, Perihan Polattaş

Gönderilme tarihi:05.03.2018

Kabul tarihi:19.12.2018

\section{Özet}

Amaç:Onkoloji hastalarında kemoterapi ajanlarının kullanılması, bu hastalarda uygun desteğin de sağlanabileceği santral yolların kullanımını zaruri kılmışır. Biz girişimsel radyoloji ünitesinde erişkin hastalara başarıla takılan 498 port kateterin, erken ve geç komplikasyonlarını retrospektif olarak değerlendirdik. Port kateterleri takan ve kullanan sağık personelinin karşılaşabileceği komplikasyonları öğrenmesini, dikkatli ve hijyenik kullanımının önemini bildirmeyi amaçladık.

Gereç ve Yöntem:Çalışmaya girişimsel radyoloji bölümümüzde ultrason ve floroskopi eşliğinde internal juguler ven yoluyla iki yıl boyunca 498 hastaya perkütanöz venöz girişle taktığımız port kataterleri retrospektif olarak erken ve geç komplikasyonlarını değerlendirdik. Port kateter takılan hastaların yaş, cinsiyet, primer tanısı, takılan portun cinsi, anestezinin türü, erken ve geç komplikasyonları, eksplantasyon nedenleri saptandı ve bilgisayar ortamına kaydedildi. İşlemden sonraki 2 hafta içerisindeki komplikasyonlar erken, daha sonraki komplikasyonlar geç olarak kabul edildi.

Bulgular:Hastaların $195^{\prime} \mathrm{i}$ kadın $(\% 39,2), 303$ 'ü erkekti $(\% 60,8)$. Hastaların asıl tanılarına bakıldığında en büyük grubu 413 hasta $(\% 82,9)$ ile gastrointestinal sistem maligniteleri oluşturmuştu. Başarıyla yerleştirdiğimiz tüm port kateterlerimizde pnömotoraks, yanlış arteryel giriş, pleksus irritasyonu ve hava embolisi gibi erken major komplikasyonlar gelişmedi. Sadece 3 vakada erken dönemde hematom gelişti. Geç komplikaslarımızın oranı $\% 3,4$ idi.

Sonuç:Major erken komplikasyonlar olmaksızın görüntüleme kılavuzluğunda gögüs duvarına yerleştirilen port kateterlerin, düşük komplikasyon oranına sahip olması nedeniyle cerrahi tekniğe göre üstünlük göstermektedir. Retrospective evaluation of 498 venous access port implantations and complications in adult patients.

Anahtar Kelimeler:Ultrasonografi, floroskopi, port kateter.

Eldeş T, Akmangit I, Dede D, Yıldırım N, Sayın B, Polattaş P. Erişkin hastalarda 498 deri alti port kateter uygulamalari ve komplikasyonlarinin retrospektif değerlendirilmesi. Pam Tıp Derg 2019;12:209-214.

\begin{abstract}
Purpose:Application of chemotherapy agents in oncology cases has necessitated the use of central routes to provide appropriate support for these patients. We retrospectively evaluated the early and late complications of 498 port catheters successfully implanted in adult patients in our interventional radiology unit. We aimed to inform health personnel that implant and use port catheters about possible complications and emphasize the importance of careful and hygienic use of these materials.

Materials and Methods:Over two years, we retrospectively evaluated the early and late complications of port catheters implanted in 498 patients through ultrasound- and fluoroscopy-guided internal jugular venous and percutaneous venous access in our interventional radiology department. Age, sex, primary diagnosis, type of port implanted, type of anesthesia, early and late complications, and reasons for explantation were determined and recorded in a computer environment. Complications that developed within two weeks after the procedure were considered as early and those after this period were regarded as late complications.

Results: Of the patients, 195 were female (39.2\%) and 303 were male $(60.8 \%)$. When the main diagnoses of the patients were examined, $413(82.9 \%)$ had gastrointestinal system malignancies. No early major complications, such as pneumothorax, improper arterial access, plexus irritation, and air embolism developed in relation to any of the implanted port catheters. Only three cases developed early hematoma. The rate of late complications was $3.4 \%$.
\end{abstract}

Tuğba Eldeş, Dr. Öğr. Üyesi. Recep Tayyip Erdoğan Üniversitesi Eğitim ve Araştırma Hastanesi Radyoloji Anabilim Dalı, RizE, e-posta: eldestugba@gmail.com (orcid.org/0000000184319534) (Sorumlu yazar)

İlkay Akmangit, Doç. Dr. Ankara Numune Eğitim ve Araştırma Hastanesi Radyoloji Kliniği, ANKARA, e-posta: ilkayakm@gmail.com (orcid. org/0000000265533639)

Doğan Dede, Uzm. Dr Ankara Numune Eğitim ve Araştırma Hastanesi Radyoloji Kliniği, ANKARA, e-posta: dogan.dede@mynet.com ( orcid. org/0000000285423808)

Nilgün Yıldırım, Uzm. Dr. Ankara Numune Eğitim ve Araştırma Hastanesi Radyoloji Kliniği, ANKARA, e-posta: yildirimnilgun@yahoo.com (orcid.org/0000000165060336)

Bige Sayın, Uzm. Dr. Ankara Numune Eğitim ve Araştırma Hastanesi Radyoloji Kliniği, ANKARA, e-posta: bigesayin99@yahoo.com (orcid. org/0000000328245942)

Perihan Polattaş, Uzm. Dr. Ankara Numune Eğitim ve Araştırma Hastanesi Radyoloji Kliniği, ANKARA, e-posta: perisoydinc@hotmail.com (orcid.org/0000000306737540) 
Conclusion: Imaging guided implantation of chest ports, having a considerably lower complication rate without any early major complications, seems superior to surgical placement.

Key Words: Ultrasonography, fluoroscopy, venous access port.

Eldeş T, Akmangit I, Dede D, Yıldııı N, Sayın B, Polattaş P. Retrospective evaluation of 498 venous access port implantations and complications in adult patients. Pam Med J 2019;12:209-214.

\section{Giriş}

Onkoloji hastalarında kemoterapi ajanlarının kullanılması bu hastalarda uygun desteğin de sağlanabileceği santral yolların kullanımını zaruri kılmıştır. Uzun süreli tedavi sırasında, damar yolu bulma, sık damar yolu açılmasına ikincil damarlarda gelişen harabiyet, hastada oluşturduğu ağrı ve anksiyete tedavi uyumu ve devamlılığını sağlamada sorunlar oluşturmaktadır. Görüntüleme eşliğinde yerleştirilen port kateterler son birkaç dekadta bu açıdan çok tercih edilen bir yöntem olmuştur [1]. Günümüzde girişimsel radyoloji üniteleri sadece port kateter takılmasını değil ortaya çıkabilecek komplikasyonların değerlendirilmesini ve tedavisini yönlendiren birim haline gelmiştir [2].

Biz girişimsel radyoloji ünitesinde erişkin hastalara başarıyla takılan 498 port kateteri, erken ve geç komplikasyonlarını retrospektif olarak değerlendirmeyi amaçladık. Port kateterleri takan ve kullanan sağlık personelinin karşılaşabileceği komplikasyonları öğrenmesi, dikkatli ve hijyenik kullanımın önemini anlamasını planladık. Elde edilen sonuçların değerlendirilmesi ve analizi ile komplikasyonların uygun ve etkin tedavi edilerek oldukça pahalı olan port kateterlerin kullanım süresinin uzatılıp bu araçlardan optimum yarar sağlanmasını hedefledik.

\section{Gereç ve yöntem}

Çalışmaya girişimsel radyoloji bölümümüzde ultrasonografi ve floroskopi eşliğinde internal juguler ven yoluyla iki yıl boyunca 498 hastaya perkütanöz venöz girişle taktığımız port kataterleri retrospektif olarak değerlendirdik. Çalışmamız tezden türetilmiş olup veriler retrospektif olarak hasta dosyalarından ve hastane bilgi işlem programından elde edildi. Port kateter takılan hastaların yaş, cinsiyet, primer tanısı, takılan portun cinsi, anestezinin türü, erken ve geç komplikasyonları, eksplantasyon nedenleri saptandı ve bilgisayar ortamına kaydedildi. İşlemden sonraki 2 hafta içerisindeki komplikasyonlar erken; daha sonraki komplikasyonlar geç olarak kabul edildi. Hastanemizde Deltec (SIMS Deltec, ABD) ve Polysite (Perouse Laboratoires, Fransa) marka portlar kullanılmaktaydı. Portlar, katetere iliştirilmiş tek ya da çift lümenli reservuar gövdeden oluşur. İntravasküler kateter kısmı diğer santral venöz kateterlerde (SVK) olduğu gibi silikon ve poliüretandan yapılmıştır. Silastik materyalden yapılmış kalın enjeksiyon membranı, titanyum ya da plastik bir reservuar gövdeye sarılmıştır.

Tüm implantasyon işlemleri skopi odasında, lokal anestezi altında gerçekleştirildi. Hiçbir hastaya genel anestezi verilmedi. Kan trombosit sayısı $50.000 / \mathrm{mm}^{3}$ 'ten düşük ve INR'si 1,5 'den yüksek olan hastaların koagülasyon parametrelerinin uygun kan transfüzyonuyla düzeltilmesinden sonra işleme başlandı.

Cilt giriş yeri steril teknikle hazırlanmadan önce internal juguler venler ultrasonografi ile değerlendirildi. Giriş için öncelikle sağ internal juguler ven (IJJ) tercih edildi. Sağ IJJV tıkalı ise ya da sol dominantsa sol kullanıldı. Mastektomili hastalarda mastektomi yapılmayan taraftaki IJV'den giriş yapıldı. İmplantasyon yapılacak taraf mandibuladan memenin inferioruna kadar ve sternumdan mid-aksiller çizgiye kadar geniş̧̧e alanda cerrahi cilt temizliği yapıldı. Işlem sırasında hasta, işlemi yapan radyolog ve yardımcı personel maske ve bone taktı.

Venöz ponksiyon sonografi kılavuzluğunda, steril giydirilmiş 7,5 MHz lineer prob (Logiq 200 Pro, GE, ABD) kullanılarak yapıldı. Hastaların çoğunda venöz giriş için $18 \mathrm{G}$ venöz iğneler kullanıldı. Supraklaviküler düzeyde küçük bir insizyon ve $18 \mathrm{G}$ venöz iğne ile girildikten sonra $0,889 \mathrm{~mm}$ kılavuz tel inferior vena kavaya ilerletildi. Tel üzerinden ayrılabilir kılıf (peelaway sheath) yerleştirildikten sonra floroskopi altında (Gen-x 800, Swissray), kılavuz telin ucu atrio-kaval bileşkede ya da sağ atriyumun üst kısmında olacak şekilde tutularak telin damar dışındaki kısmı işaretlenerek intravasküler kateter boyu ölçüldü. Daha sonra işlemin ikinci 
aşaması olan subkütan cep açılmasına geçildi. Pektoral bölgede klavikulanın yaklaşık 3-4 cm kaudaline lokal anestezik infüzyonunu takiben 11 numara bistüri ile implante edilecek porta uygun olacak şekilde yaklaşık 2-3 cm'lik bir insizyon açıldı. İnsizyondan sonra subkutan dokuda künt diseksiyonla portun sığabileceği büyüklükte cep açıldı. Kanama kontrolü için gerektiğinde uygun teknikle kanayan damar bağlandı. Port cebinin gerektiğinden büyük olmamasına ve portun cebe güçlükle yerleştirilebileceği kadar dar olmamasına dikkat edildi. Port cebi açıldıktan sonra, port setinden çıkan trokar ile cep ile venöz giriş yeri arasında tünel açıldı. Trokarın arkasına takılan kateter tünelden geçirildi. Cep lokalizasyonunda port ve kateter birleştirildi, içi serum fizyolojikle yıkandı ve kateter daha önce ölçülen intravasküler uzunluğuna uygun şekilde kesildi. Venöz girişte bekleyen kılavuz tel ve etrafında peel-away kılıftan, kateterin intravaskülere girişini sağlayabilmek için, kılavuz tel çekildi. Kılıf ucu hava girmesini önlemek için parmakla kapatıldı ve vakit kaybetmeden kateter kılıftan içeri gönderildi. Kılıf soyularak kateter yavaş yavaş intravasküler ilerletildi. Sonra kateter ucunun pozisyonu ve venöz giriş yerinde olası kink oluşumu bakımından kontrol edildi. Daha sonra bir Huber iğne ile porta girilerek $100 \mathrm{U} / \mathrm{ml}$ heparin içeren serum fizyolojik solüsyon ile yıkama yapılarak geçiş kontrol edildi. İnsizyon yerleri 3-0 ipek ile sütüre edildi. İşlemden 4 saat sonra posteroanterior akciğer grafisi, işlemden sonra uygun antibiyotik profilaksisi, yara ve kateter bakımı ve 2 hafta sonra dikişlerin alınması önerileriyle hastalar servislerine gönderildi. Yerleştirdiğimiz tüm port kateterin, erken ve geç komplikasyonlarını değerlendirdik. Tüm verilerle tanımlayıcı istatistikler (sayı ve yüzde) kullanıp tanımlayıcı sonuçlar ortaya çıkarmayı amaçladık.

\section{Bulgular}

Girişimsel radyoloji ünitesinde deri altı port kateter takılan 21-84 yaşları arasında (ortanca 55) olan 498 hasta çalışmaya alındı. Hastaların 195'i kadın (\%39,2), 303'ü erkekti. 9 hastaya iki kez port takıldı.

Hastaların asıl tanılarına bakıldığında en büyükgrubu413hasta(\%82,9)ilegastrointestinal sistem maligniteleri oluşturmuştu. En sık takılan taraf, primer tanıları ve kullanılan port cinsleri ile beraber Tablo 1'de verilmiştir.

Hastaların \%92'sinde sağ IJJV yoluyla girişim yapıldı. 40 hastada (\%8) sol İJV kullanıldı. Tüm hastalarda İJV girişimi başarı ile sağlandı. Deltec ve Polysite marka port kullanımı hemen hemen eşit saptandı.

Hiçbir hastada erken dönemde majör komplikasyon izlenmedi (Tablo 2). Sadece 3 vakada erken dönemde hematom gelişti. Lokal kompresyon ve portun üç gün kullanılmaması önerildi. Hematom rezorbe olduktan sonra portlar tekrar kullanılmaya başlandı.

Tablo 1. Venöz port kateter takılan hastaların tanıları, takılan taraf ve port cinsleri.

\begin{tabular}{lll}
\hline & Sayı & Yüzde \\
\hline Primer Tanılar & 413 & $\% 82,9$ \\
Gastrointestinal tümörler & 19 & $\% 3,8$ \\
Meme karsinomu & 13 & $\% 2,6$ \\
Hematolojik malignansi & 4 & $\% 0,8$ \\
Genitoüriner malignansiler & 49 & $\% 9,8$ \\
Diğer & & \\
Girişim Yeri & 458 & $\% 92$ \\
Sağ internal juguler ven & 40 & \\
Sol internal juguler ven & & $\% 51$ \\
Venöz port Cinsi & 254 & 49 \\
Deltec & 244 & \\
Polysite &
\end{tabular}


Tablo 2. İzlemde ortaya çıkan komplikasyonlar.

\begin{tabular}{lllll}
\hline Komplikasyon & Sayı & Yüzde & Tedavi & Sonuç \\
\hline $\begin{array}{l}\text { Erken } \\
\text { Hematom }\end{array}$ & 3 & $\% 0,6$ & kompresyon & başarılı \\
$\begin{array}{l}\text { Geç } \\
\text { Cep enfeksiyonu }\end{array}$ & 5 & $\% 1$ & antibiyotik tedavi & port çıkarıldı \\
$\quad$ IJJV trombozu & 4 & $\% 0,8$ & antikoagülan tedavi & 2 hastada port çıkarıldı \\
$\quad \begin{array}{l}\text { Deri perforasyonu } \\
\text { Kateter migrasyonu }\end{array}$ & 4 & $\% 0,8$ & port çıkarıldı & tedavi bitimi \\
Toplam & 1 & $\% 0,2$ & port çıkarıldı & karşı taraftan takıldı \\
\hline
\end{tabular}

İnternal juguler ven (İJV)

Geç dönemde 5 hastada port cep enfeksiyonu gelişti. Antibiyotik tedavisi başlanan hastaların portları çıkarıldı. Bir hastada port intiyacı devam ettiği için tekrar karşı taraftan takıldı.

4 hastamızda da semptomatik juguler ven trombozu ortaya çıktı. Düşük molekül ağırlıkı heparin tedavisi önerilen hastaların 2'sinde port korundu, diğerlerinde port çıkarıldı.

Hastaların 4'ünde port üzerindeki deride perforasyon gelişti. Bu hastaların port sistemi çıkarıldı. 3 hastaya port intiyacı devam ettiği için tekrar port takıldı.

Morbid obes bir bayan hastamızda işlemden 1 ay sonra katerin çalışmadığı saptandı. Floroskopi altında bakıldığında kateter ucunun santral vende olmadığı ve port sisteminin yumuşak doku içerisinde aşağı kaydığı izlendi. Port çıkarıldıktan sonra başka bir seansta diğer tarafa port takıldı. On sekiz hastada tedavi bitimi nedeniyle 12 hastada da komplikasyon nedeni ile port çıkarıldı.

\section{Tartışma}

Port yerleştirilmesi için kullanılan radyolojik ve cerrahi girişim tekniği birbiri ile benzerdir. Cerrahi teknikte anatomik noktalar dikkate alınıp ponksiyon yapılır, kateter yerleştirildikten sonra kateter pozisyonu akciğer grafisi ile değerlendirilir. Radyolojik yöntemde ise ultrasonografi (US) ve floroskopi kullanılmakta; girilecek ven gözle görülerek ponksiyon yapılmaktadır. Radyolojik yöntemde kateterin yönelimi ve ucunun yeri hasta girişimsel radyoloji ünitesinde iken floroskopi ile anlaşılabilir. Görüntüleme kılavuzluğunda yapılan işlemler, kılavuzsuz ortaya çıkabilecek pnömotoraks, hemotoraks, arter ponksiyonu, sinir hasarı, aritmi ve kateter malpozisyonu intimalini belirgin düşürmekte ve işlem süresini kısaltmaktadır [2, 3]. Real-time görüntüleme kılavuzluğunda başarı oranı \%96-100'dür, ilk denemede hastaların \%78-96'sında kanülasyon sağlanır. Anatomik teknikte başarı oranı \%52-95'tir, ilk denemede başarı hastaların ancak \%38-52'sinde sağlanabilir. Görüntüleme eşliğinde yapılan işlemlerde komplikasyon oranı \%12'lerden $\% 0-2$ 'ye inmektedir [4, 5]. Ultrasonografinin bir başka avantajı da \%5,5'lara varan sıklıkta gelişebileceği gösterilmiş olan venöz varyasyonları tanımlayabilmesi ve anatomik teknikle kanüle edilemeyecek hastalarda dahi başarı sağlamasıdır [6]. 2003 yılında yapılan bir meta-analizde subklavyen ven (SV) ve IJV ponksiyonunda cerrahi ve US kılavuzluğunda girişim karşılaştırılmış, US kılavuzluğunda İJV ponksiyonunun hem başarı oranının yüksek olduğu ve hem de komplikasyon oranında \%57 relatif risk azalması olduğu ortaya konmuştur [7].

Port takılırken en sık kullanılan iki ven, SV ve İJV'dir. Sağ iJV, düz bir trase izlemesi, ponksiyon başarısının yüksek olması, SV'ye göre pnömotoraks ve tromboz riskinin düşük olması nedeniyle tercih edilmektedir [8-10]. US ile sağ IJJV'nin port takmadan hemen önce değerlendirilmesi, başarı şansını artıran, tercih edilen bir yöntemdir [11].

Sol IJJV tercih edildiğinde ise duktus torasikus zedelenmesi artmaktadır. US arter ponksiyonu ve pnömotoraks riskini azaltmasına rağmen kılıf ilerletilmesinde, kılavuz tel ve kateter yerleştirmede ortaya çıkabilen bu teknik zorluklarda fayda sağlamamaktadır [11]. SV yol girişiminde US kılavuzluğunun anatomik metoda belirgin üstünlüğü olmadığı gösterilmiştir [7, 12]. 
Bu yol kullanıldığında operatör tecrübesi daha çok önem kazanmaktadır.

Cerrahi yöntemle port kateter takılan 550 hastayı değerlendiren bir çalışmada, SV yol kullanımasının, komplikasyonları bağımsız olarak artırdığı ortaya konmuştur. Bu çalışmada soldan girişimin ve port kateter ucunun üst VCS'de sonlanmasının da komplikasyon sıklığını arttırdığı gösterilmiştir. Erken komplikasyon \%1, toplam komplikasyon \%19 sıklıkta gözlenmiştir [13].

Girişimsel radyolojik yöntemle 125 vakaya SV yolla port kateter takılan bir çalışmada pnömotoraks \%1,6, erken komplikasyon ise \%11,6 sıklığında gözlenmiştir [14].

Hastanemiz girişimsel radyoloji ünitesinde takılan 1418 port vakasının retrospektif olarak incelendiği çalışmada, girişim başarısı \%100'dür. Erken komplikasyon sıklığı \%2,77 saptanmıştır. Erken komplikasyonların büyük çoğunluğunu lokal hematom oluşturmuştur. Bu çalışmada \%96 sıklıkta sağ IJJV kullanılmıştır [3]. Bu bilgiler ışığında görüntüleme eşliğinde port takılacak hastalarda sağ İJV'nin tercih edilmesi daha makul gözükmektedir. Ülkemizde, girişimsel radyoloji kılavuzluğunda, 476 port vakasının uzun dönem sonuçları Çil ve ark. tarafından yayınlanmıştır. Erken komplikasyon \%0,6, enfeksiyon $\% 2$, tromboz $\% 1,5$, deri perforasyonu
$\% 0,2$ ve toplam komplikoasyon sıklığı \%10,7 olarak bildirilmiştir [15]. Gebauer ve ark. ise, US ve flosoroskopi kılavuzluğunda 298 hastaya port kateter takılmış ve hastalar prospektif olarak takip edilmiştir. İşlem başarısı \%99'dur. Erken komplikasyon oranı \%1,3, enfeksiyon $\% 4$, tromboz $\% 0,2$ ve deri perforasyonu $\% 0,1$ sıklıkta izlenmiştir. Toplam komplikasyon oranı $\% 7,7$ olarak belirtilmiştir [16].

Bizim çalışmamızda hastaların \%92'sinde (458) sağ IJJ, \%8'inde (40) de sol IJJV kullanılmıştır. Başarı oranımız \%100'dür. Çalışmamızda pnömotoraks, arter ponksiyonu, pleksus irritasyonu, hava embolisi, aritmi gibi erken dönem komplikasyonları izlenmemiş, sadece minör kanama ve hematom gelişmiştir. Erken komplikasyon sıkığımızın düşük olması sağ IJJ'nin tercih edilmiş olmasına bağlı olabilir.

Görüntüleme eşliğinde girişimlerde tromboz ve enfeksiyon oranları cerrahi vakalara göre düşük saptanmıştır [2]. Portlar SVK'lar arasında en düşük enfeksiyon oranına sahiptir [17]. Çalışmamızda 5 hastada (\%1) port cep enfeksiyonu izlenmiştir. Literatürde \%0,3-\%5 arasında enfeksiyon hızları bildirilmiştir [1, 3 , 14]. Hastalarımızın büyük çoğunluğunun malignite nedeniyle kemoterapi aldığı göz önüne alındığında \%1 sıklıkta enfeksiyon kabul edilebilir ve literatürle uyumludur (Tablo 3).

Tablo 3. Literatürde port kateter komplikasyonları.

\begin{tabular}{lcccccc}
\hline & sayı & pnömotoraks & enfeksiyon & tromboz & deri perforasyonu & $\begin{array}{l}\text { toplam } \\
\text { komplikasyon }\end{array}$ \\
\hline Morris ve ark [1]. & 102 & $\% 0,9$ & $\% 5$ & $\% 4$ & $\% 1$ & $\% 24$ \\
Funaki ve ark [2]. & 80 & $\% 0$ & $\% 3$ & $\% 1$ & $\% 0$ & $\% 4$ \\
Lorch ve ark [14]. & 125 & $\% 1,6$ & $\% 2,4$ & $\% 0$ & $\% 0,8$ & $\% 16$ \\
Yip ve Funaki [10] & 118 & $\% 0$ & $\% 4,2$ & $\% 1,7$ & $\% 0,8$ & $\% 6,8$ \\
Çil ve ark [15]. & 476 & $\% 0$ & $\% 2$ & $\% 1,5$ & $\% 0,2$ & $\% 10,7$ \\
Gebauerve ark [16]. & 299 & $\% 0$ & $\% 4$ & $\% 0,2$ & $\% 0,1$ & $\% 7,7$ \\
Dede ve ark [3]. & 1418 & $\% 0$ & $\% 0,3$ & $\% 0,6$ & $\% 0,8$ & $\% 4,7$ \\
Çalışmamı & 498 & $\% 0$ & $\% 1$ & $\% 0,8$ & $\% 0,8$ & $\% 3,4$ \\
\hline
\end{tabular}


Çalışmamızın sınırlılığı port kateterler uzun dönem kullanılmasından dolayı bir kısmının veri toplama sırasında komplikasyonsuz da olsa hasta üzerinde olmasıdır.

Sonuç olarak port kateterlerin radyolojik görüntüleme eşliğinde takılması son zamanlarda tercih edilmeye başlanmıştır. Girişimsel radyoloji ünitelerinde ultrasonografi ve floroskopi kılavuzluğunda, juguler ven yoluyla port kateter takılması başarılı, düşük komplikasyonlu ve güvenilir saptanmıştır. Ultrasonografi kılavuzluğu girişim komplikasyonlarını sıfıra yaklaştırmış, floroskopi kullanılması da kateter ucunun yerini tam ayarlamayı sağlayarak geç dönem komplikasyonları azaltmıştır. Bu durum, port uygulamalarının görüntüleme kılavuzluğunda yapılmasının altın standart haline gelmesi fikrini desteklemektedir.

Çıkar İlişkisi: Yazarlar çıkar ilişkisi olmadığını beyan eder.

\section{Kaynaklar}

1. Morris SL, Jaques PF, Mauro MA. Radiology-assisted placement of implantable subcutaneous infusion ports for long-term venous access. Radiology 1992;184:149151. https://doi.org/10.1148/radiology.184.1.1609072

2. Funaki B, Szymski GX, Hackworth CA, Rosenblum JD, et al. Radiologic placement of subcutaneous infusion chest ports for long-term central venous access. AJR Am J Roentgenol 1997;169:1431-1434. https://doi. org/10.2214/ajr.169.5.9353475

3. Dede D, Akmangit I, Yildirim ZN, Sanverdi E, Sayin B. Ultrasonography and fluoroscopy-guided insertion of chest ports. Eur J Surg Oncol 2008;34:1340-1343. https://doi.org/10.1016/j.ejso.2007.12.001

4. Namyslowski J, Patel NH. Central venous access: A new task for interventional radiologists. Cardiovasc Intervent Radiol 1999;22:355-368.

5. Teichgraber UK, Benter T, Gebel M, Manns MP. A sonographically guided technique for central venous access. AJR Am J Roentgenol 1997;169:731-733. https://doi.org/10.2214/ajr.169.3.9275887

6. Denys BG, Uretsky BF. Anatomical variations of internal jugular vein location: impact on central venous access. Crit Care Med 1991;19:1516-1519.

7. Hind D, Calvert N, McWilliams R, et al. Ultrasonic locating devices for central venous cannulation: metaanalysis. BMJ 2003;327:361. https://doi.org/10.1136/ bmj.327.7411.361

8. Tan PL, Gibson M. Central venous catheters: the role of radiology. Clin Radiol 2006;61:13-22. https://doi. org/10.1016/j.crad.2005.07.010
9. Trerotola SO, Kuhn-Fulton J, Johnson MS, Shah H, Ambrosius WT, Kneebone PH. Tunneled infusion catheters: increased incidence of symptomatic venous thrombosis after subclavian versus internal jugular venous access. Radiology 2000;217:89-93. https://doi. org/10.1148/radiology.217.1.r00oc2789

10. Yip D, Funaki B. Subcutaneous chest ports via the internal jugular vein. A retrospective study of 117 oncology patients. Acta Radiol 2002;43:371-375.

11. Onders RP, Shenk RR, Stellato TA. Long-term central venous catheters: size and location do matter. Am J Surg 2006;191:396-399. https://doi.org/10.1016/j. amjsurg.2005.10.044

12. Bold RJ, Winchester DJ, Madary AR, Gregurich MA, Mansfield PF. Prospective, randomized trial of Dopplerassisted subclavian vein catheterization. Arch Surg 1998;133:1089-1093.

13. Ignatov A, Hoffman $O$, Smith $B$, et al. An 11-year retrospective study of totally implanted central venous access ports: complications and patient satisfaction. Eur J Surg Oncol 2009;35:241-246. https://doi. org/10.1016/j.ejso.2008.01.020

14. Lorch H, Zwaan M, Kagel C, Weiss HD. Central venous access ports placed by interventional radiologists: experience with 125 consecutive patients. Cardiovasc Intervent Radiol 2001;24:180-184. https://doi. org/10.1007/s002700001721

15. Cil BE, Canyigit M, Peynircioglu B, et al. Subcutaneous venous port implantation in adult patients: a single center experience. Diagn Interv Radiol 2006;12:93-98.

16. Gebauer B, El-Sheik M, Vogt M, Wagner HJ. Combined ultrasound and fluoroscopy guided port catheter implantation--high success and low complication rate. Eur J Radiol 2009;69:517-522.

17. Groeger JS, Lucas AB, Thaler HT, et al. Infectious morbidity associated with long-term use of venous access devices in patients with cancer. Ann Intern Med 1993;119:1168-1174.

Teşekkür: Girişimsel işlemlerimiz sırasında bize desteklerinden dolayı yardımcı sağlık personellerimize teşekkür ederiz. 